\title{
EFFECT OF SHORT-TERM YOGA PRACTICES ON PSYCHOLOGICAL GENERAL WELL BEING IN MEDICAL STUDENTS
}

Manjula Mehta, Priti Taneja

1. Demonstrator. Department of Physiology, MGM Medical College, Indore, Madhya Pradesh.

2. Ex Professor \& Head. Department of Physiology, MGM Medical College, Indore, Madhya Pradesh.

\section{CORRESPONDING AUTHOR:}

Dr. Manjula Mehta, 290, Parshvanath Nagar,

Kesar Bag Road, Indore (M.P.).

E-mail: drmanjulamehta@hotmail.com

Yoga is assuming importance in improving mental health and quality of life and in the treatment of a number of psychiatric and psychosomatic disorders. Medical students are foundation of the medical profession; hence they must be aware of the alternative and adjunct therapy for the betterment of their patients. One of the most beneficial alternative therapies is Yoga therapy. Medical students must know how yoga is useful for their patients. Keeping this objective in mind, the present study was conducted on medical students to make them aware what yoga is and to encourage them to incorporate yoga in their life and to use it for the benefits of their patients as an adjunct to the medicinal treatment. The study was conducted on healthy medical students (21 males and 15 females) of age group 17-21 years in the department of physiology, Mahatma Gandhi Memorial Medical College, and Maharaja Yashwantrao Hospital, Indore. After obtaining an informed consent; and satisfying the inclusion and exclusion criteria, the psychological well being of the subjects was assessed by "Psychological General Well Being Schedule Score (Sajatovic 2003)" on the first day before the subjects started yoga practices. The students performed the yoga practices in the morning for one hour, six days in a week, for four weeks under expert's observation. The yoga practices consisted of Prayer, Omkar recitation, asana, and Pranayama. Psychological well being was assessed using the same schedule score on the last day of yoga programme. Data thus collected were compiled, tabulated and analyzed by using students' ' $t$ ' test. There was highly significant improvement in psychological well being of the students as denoted by $\mathrm{p}$ value of $<.0 .001$. Conclusion: There is a marked improvement in the psychological well being scores of the students after performing short-term yoga practices. By extending these results we suggest that short-term yoga practices can therefore make an appreciable contribution to primary prevention as well as management of various psychological and life style diseases.

KEY WORDS: Psychological General Well Being Schedule Sajatovic 2003 omkar recitation asana Pranayama student's test

INTRODUCTION: India has been the birth place of ancient discipline of yoga. For centuries, Hindu devotees have talked about the miraculous effects of yoga. In the last century, the world has woken up to yoga and its beneficial effects. Ever since the dawn of $21^{\text {st }}$ century, the health industry has been growing in leaps and bounds. The markets are flooded with various health products of all brands and compositions. Doctors around the world have echoed that yoga can relieve a number of potential life threatening physical and mental illnesses.

From the Yogic viewpoint the body and the mind (together with the emotions) are so interrelated that they are actually inseparable. Whatever affects the body must influence the 
mind and vice-versa. Since the mind is present throughout the body and permeates its every atom, the Yoga techniques which we perform to stretch, strengthen and otherwise improve and develop the body must have a correspondingly profound effect on the mind and the emotions as well.

To live a happy and healthy life is the ultimate goal of every human being. The feeling of happiness and satisfaction subjectively experienced by individuals has been termed as psychological wellbeing1. A few other terms like subjective wellbeing, quality of life, mental health and life satisfaction have been used as synonyms of Psychological Wellbeing (PWB). In recent years there has been global interest in the study of PWB and quality of life. Psychological or subjective wellbeing is more a question of our attitude and approach to life situations.

Swami Sivananda Saraswati of Rishikesh explained yoga as an "integration and harmony between thought, feeling, and deed; or integration between head, heart, and hand". Through the practice of yoga, awareness develops of the interrelation between emotional, mental, and physical levels.

From the yogic perspective body, mind, and spirit are integral but independent parts so there should be a holistic approach towards the health. Thus yogic meaning of well being is physical fitness, mental agility, and spiritual verve. ${ }^{2}$ Since most diseases are psychomatic, the psycho-somato-spritual approach of yoga has been found effective in managing stress-related problems. Thus yoga is a preventive and promotive science of health and wellbeing. ${ }^{3}$

Scientific and technological progress all over the globe has made mankind highly sensitive and also creative. Association with this progress is the emergence of two challenges - pollution and stress. The challenge of pollution may be taken care of effectively but on the second front management of stress is very difficult. In spite of increasing research all over the globe, the decreasing 'Quality of Life' and social unrest are on rise.

Presently mental health disorders are on the rise throughout the world as a result of stressful life style which results in anxiety, fear, depression, inferiority and similar emotions. Apart from causing mental disturbances, stress usually causes disturbances in physical health also. Therefore, learning the management of negative mental health is an important aspect for complete health and disease free life. As described by WHO (1946), "Health is a state of complete physical, mental, and social well being and not merely absence of disease or infirmity". This definition has been amplified to include the ability to "lead a socially and economically productive life". Yoga offers comprehensive solutions for managing health as a whole. Deep relaxation and calming down of the mind lead to beneficial changes in physiological process as seen by slowing of pulse and respiratory rates, and reduced oxygen consumption as well as help in solving their psychological conflicts, suppressions and hypersensitivity which are recognized as triggering factors for psychosomatic problems. The practice of Yoga yogic breathing exercises helps to maintain both physical and mental health, which cannot be done by either taking pills or drinking potions.

The specific effects of yogic relaxation exercises are

- Stress reduction

- Increase self awareness

- Better mental performance

- Improved overall health

Medical students of today are the physicians of tomorrow and a good physician must be physically and mentally healthy and lead a quality life. The aim of this study is to study the 
short-term impact of a comprehensive but brief lifestyle intervention, based on yoga, on psychological well being of medical students.

Yoga and its effects on the body are within the realm of physiology as it establishes harmony among various body systems. Yoga is by no means out of place in a course on physiology; and many authors have included yoga in the curriculum of physiology in their textbooks. Hence, it would be better if $1^{\text {st }}$ year medical students are introduced and made aware of yogic practices and their beneficial effects. That is why this study was undertaken on $1{ }^{\text {st }}$ year medical students; so that they could experience these effects on their own.

Aims and objectives: To study the effect of short-term yoga practices on psychological well being of medical students.

Material and Methods: This study was carried out in the Department of Physiology, Mahatma Gandhi Memorial Medical College and Maharaja Yashwantrao Hospital, Indore

Study design: Prospective Study

Sample Type: Purposive

\section{Inclusion Criteria:}

- First year medical students of MGM Medical College, Indore who gave consent to participate in the project and undergo investigations

- Students free from any respiratory or other serious illness

- Students not involved in yoga practices previously

\section{Exclusion Criteria:}

- Students not ready to give consent to be included in the study and undergo any investigations

- Smokers (Cigarettes, Bidis, Tobacco chewing etc).

- Students suffering from any Respiratory disorder

- Students suffering from any chronic illness.

Sample size: 36 participants- medical students of Mahatma Gandhi Memorial Medical College, Indore. To start with 66 students had given consent for this study; but because of some or other reasons only 36 could continue till end. So, the final data collected and compared were of 36 students.

Compliance: The subjects should have at least $80 \%$ attendance in the yoga sessions Material used: Psychological General Well Being Schedule Score (Sajatovic 2003) ${ }^{4 \mathrm{~s}}$

Methodology: The study was conducted on healthy medical students (21 males and 15 females) of age group 17-21 years in the department of physiology, Mahatma Gandhi Memorial Medical College, and Maharaja Yashwantrao Hospital, Indore. After obtaining ethical clearance and satisfying the inclusion and exclusion criteria; an informed consents was taken and the psychological well being of the subjects was assessed on a standard pre-tested schedule containing 22 items on the first day before the subjects started yoga practices. Then the students performed the yoga practices in the morning for one hour, six days in a week, for four weeks under expert's observation. The yoga practices consisted of Prayer, Omkar recitation, Asana, Pranayama, and breathing exercises. Psychological well being was again assessed on the last day using same schedule. 
Yoga schedule: The students were informed about the programme, and made comfortable and oriented for initial two days. Then they were subjected to following yoga programme:

1. Prayer and Omkar recitation in Padmasana/Sukhasana.

2. Stretching exercise includes neck, shoulder, and arm rotation; elbow, wrist, and finger movements; waist movements; knee and ankle rotation; and toe movements.

3. Quick relaxation in Shavasana (Corpse Pose)

4. Asana

\section{Standing postures}

Tadasana

Triyakasana

Trikosana

Pawanmuktasana

Katichakrasana

Padhastasana

\section{Sitting Postures}

Shashankasana

Bhunamanasana

Janushirasana

Paschimuttanasana

Padangusthana

Utthitpadasana

\section{Surya Namaskar}

5. Deep relaxation in Shavasana /Yog nidra

6. Pranayama

7. Omkar recitation in Padmasana/Sukhasana

Psychological General Well Being Schedule is an index of measuring subject's general well being. In the late sixties Harold Dupuy, psychologist at the National Centre for Health Statistics, developed his Psychological General Well Being Schedule, a questionnaire of 68 items to measure the degree of 'happiness' of the American population or the potential psychological distress. The PGWBI has been validated and used in many countries on large samples of the general population and on specific patient groups. The questionnaire was considered one of the first generic measures of health-related quality of life with specific interest to mental health. Some years after Dupuy 5 together with John E. Ware revised the questionnaire and a final version of 22 selected items was validated under the name of PGWB Index (PGWBI). So the PGWBI is a validated 22-item multiple-choice questionnaire that measures self-reported intrapersonal affective or emotional states reflecting a sense of subjective well-being or distress. It includes subscales for anxiety, depressed mood, positive well-being, self-control, general health and vitality. Each response is rated on a six-point Likert scale ranging from 0 (most distressed) to 5 (highest level of well-being). These are summed to provide the composite score, which ranges from 0 (most negative affective experience) to 110 (most positive affective experience). The higher the score, the better is the well-being. Its approach may be seen as more "positive" than other quality-of-life scales because it measures well-being rather than disability.

Statistical analysis and results: Table 1 shows that in the whole group the mean value of PGWBS before yoga was 69.97 and after yoga it was 80.06 with p value of 0.000 . In males the 
mean value of PGWBS was 70.523 before yoga and 79.381 after yoga with p value of 0.013 . In females the mean value of PGWBS was 69.200 before yoga and 81.00 after yoga with p value of 0.001 . These observations indicate that the increase in PGWBS score is statistically significant in all the three groups but is more marked in females as compared to males.

Table 1: Mean PGWBS Score with p values before and after yoga

\begin{tabular}{|l|c|c|c|c|c|}
\hline Group & No. of Participants & $\begin{array}{c}\text { Mean PGWBS } \\
\text { Before Yoga } \pm \text { SD }\end{array}$ & $\begin{array}{c}\text { Mean PGWBS } \\
\text { After Yoga } \pm \text { SD }\end{array}$ & $\begin{array}{c}\mathbf{t} \\
\text { Value }\end{array}$ & $\begin{array}{c}\mathbf{p} \\
\text { Value }\end{array}$ \\
\hline Males & 21 & $70.523 \pm 14.644$ & $79.381 \pm 14.783$ & -2.725 & 0.013 \\
\hline Females & 15 & $69.200 \pm 8.579$ & $81.000 \pm 8.872$ & -4.171 & 0.001 \\
\hline Total & 36 & $69.97 \pm 12.346$ & $80.06 \pm 12.531$ & -4.548 & 0.000 \\
\hline
\end{tabular}

Table 2 shows number and percentage of subjects in various ranges of PGWBS score before and after yoga. It was found that there is a definite shift of good number subjects from lower ragne of PGWBS score to higher range of PGWBS score after performing yoga for 4 weeks. It is also obseved that around $20 \%$ subjects $(n=4)$ have even crossed $100 \%$ value which is remarkable.

Table 2: Number and percentage of subjects in various ranges of PGWBS score before and after yoga

\begin{tabular}{|c|c|c|c|c|c|c|c|c|c|c|c|c|}
\hline \multirow{3}{*}{$\begin{array}{c}\text { Range of } \\
\text { PGWBS } \\
\text { Score }\end{array}$} & \multicolumn{4}{|c|}{ Male } & \multicolumn{4}{|c|}{ Female } & \multicolumn{4}{|c|}{ Total } \\
\hline & \multicolumn{2}{|c|}{$\begin{array}{c}\text { Before } \\
\text { yoga }\end{array}$} & \multicolumn{2}{|c|}{$\begin{array}{l}\text { After } \\
\text { yoga }\end{array}$} & \multicolumn{2}{|c|}{$\begin{array}{c}\text { Before } \\
\text { yoga }\end{array}$} & \multicolumn{2}{|c|}{$\begin{array}{l}\text { After } \\
\text { yoga }\end{array}$} & \multicolumn{2}{|c|}{$\begin{array}{c}\text { Before } \\
\text { yoga }\end{array}$} & \multicolumn{2}{|c|}{$\begin{array}{l}\text { After } \\
\text { yoga }\end{array}$} \\
\hline & No. & $\%$ & No. & $\%$ & No. & $\%$ & No. & $\%$ & No. & $\%$ & No. & $\%$ \\
\hline$<80$ & 15 & 71.42 & 12 & 57.14 & 13 & 86.67 & 06 & 40 & 28 & 77.76 & 18 & 50.00 \\
\hline $80-100$ & 6 & 28.58 & 5 & 23.81 & 2 & 13.34 & 7 & 46.67 & 8 & 22.24 & 14 & 38.88 \\
\hline$>100$ & 0 & 0 & 4 & 19.05 & 0 & 0 & 2 & 13.33 & 0 & 0 & 4 & 11.12 \\
\hline Total & 21 & 100 & 21 & 100 & 15 & 100 & 15 & 100 & 36 & 100 & 36 & 100 \\
\hline
\end{tabular}

DISCUSSION: Psychological General Wellbeing Schedule is an index of measuring person's general well being. It includes subscales for anxiety, depression, positive well being, self control, general health and vitality. Its approach may be seen more "positive" than other 'Quality of Life' scales because it measures well being rather than disability. Cheerfulness, optimism, self control, freedom from frustration, anxiety, and loneliness have been accepted as indicators of psychological general wellbeing by certain researchers ${ }^{6}$. Certain researchers have reported yoga as an instrument for psychological transformation. ${ }^{7}$ Shavasana is an effective measure for alleviating depression. ${ }^{8}$

It has been observed in various previous studies as well as in the present study that psychological status of an individual is greatly influenced by yogic life style. Several studies report that yoga may reduce anxiety and stress, improve mood, and help in personality development in healthy young adults ${ }^{9-12}$.

In the present study we also observed a significant improvement in the psychological well being of the participants. It was observed that there was marked increase in the mean values of PGWBS score after yoga in all the three groups and this increase was significant statistically as denoted by $\mathrm{p}$ values. If we look at the observations gender wise it shows that 
improvement is more marked in females than males which is also statistically significant as denoted by $\mathrm{p}$ values of 0.001 in females and 0.013 in males. Another important observation (table 2) was that initially $71.42 \%(\mathrm{n}=15)$ males were having PGWBS score $<80$ and $28.58 \%$ $(n=06)$ males had PGWBS score 80-100 and not a single participant had a score $>100$. After performing yoga the figures changed to $57.14 \%(n=12)$ with PGWBS score of $<80,23.81 \%$ $(n=05)$ had a score between $80-100$, and 19.05\% (n=04) had a score of $>100$.

In females the observations revealed that before yoga $86.67 \%(n=13)$ females had a score $<80$ and $13.34 \%(n=2)$ had a score of $80-100$ and not a single participant had a score of 100. After performing yoga it was observed that $40 \%(n=06)$ had a score $<80,46.67 \%(n=07)$ had a score $80-100$, and $13.33 \%(n=02)$ had a score of $>100$.

These observations indicate that the shift of the participants from lower range of PGWBS scores to a higher range of PGWBS score is also more marked in females as compare to males. It is a well known fact happy and healthy woman is the key feature of a happy and healthy family. The results of the present study clearly indicate that by incorporating the yogic life style in women's life can be beneficial to achieve this.

A study conducted on medical students to see the beneficial effects of yoga also revealed an improvement in various parameters such as better sense of well being, feeling relaxed, improvement in concentration, self confidence, efficiency, good interpersonal relationship, improved attentiveness, lowered irritability, and optimistic outlook towards life were some of the beneficial effects experienced by the yoga group indicated by feedback. ${ }^{13}$

Another study reported improvement in stress perception and reduction in State and Trait Anxiety in emotionally stressed females after participating in the yoga training. ${ }^{14,15,16}$

Another study conducted to compare the effects of relaxation, visualization, and yoga on mood change and perception of vitality reported that yoga had greater beneficial effects than visualization and simple relaxation techniques. ${ }^{17}$

A student under optimal stress does bring out his or her best, however extremes of stress can result in stress induced disorders and deteriorating performance. Can yoga be of benefit in stress induced effects in medical students? The answer is 'yes'. A study conducted MBBS students to determine the benefit, if any, of yogic practices on anxiety status during routine activities and prior to examination revealed the beneficial role of yoga in not only causing reduction in basal anxiety level but also attenuating the increase in anxiety score in stressful state such as examinations. ${ }^{18}$

India has been the birth place of ancient discipline of Yoga. Today, Yoga is enjoying tremendous popularity across the globe and is being practiced as a healthy way of life. Recently, yoga has been adopted as an approach to health within alternative medicine. ${ }^{19,20}$ The modern medical system is also endorsing the health benefits of Yoga in general. It is proved beyond doubt from many scientific researches that Yoga is very useful in prevention and management of many psycho-somatic disorders.

CONCLUSION: Thus with this discussion we can conclude that yogic life style definitely has a beneficial effect on person's well being thus improving mental and psychological health.

\section{RECOMMENDATIONS:}

* General population, irrespective of age and sex, with yoga being incorporated in their daily routine has only been examined occasionally. So future research could be focused 
on the analysis of healthy yogic life style in general population and development of yoga schedule effective and feasible for everyone to reach health for all by 2020 .

* It is always said that 'prevention is better than cure' and it should be a cost-effective strategy for better health. The primary prevention involves not only reducing the risks but also the active enhancement of the positive health. One of the implications of the results of this study is that positive health can be achieved by yogic life style.

* It is suggested that yoga be introduced at school level in order to improve physical and mental health thereby improving overall performance of students

* Yoga practices on account of their positive effects on psychological well being of an individual can be used in the management of psychological problems.

\section{BIBLIOGRAPHY :}

1. Okun, M. A. \& Stock, W. A. Corrleates and components of SWB. Journal of Applied Genetology, 1984; 6.1: 95-112

2. Bhushan, L. I. A yogic model of mental health. Indian Journal of Psychological Issues, 1994; 1 (3): $1-5$

3. Dr L.I. Bhushan (Sannyasi Yogasindhu). Yogic Lifestyle and Psychological Well Being. Sivananda Math Yoga Magazine Bihar School of Yoga 1998; 4

4. Sajatovic. M. et al. "Rating scales in mental health". Panther Pub Pvt Ltd. 2003; 2nd Edition

5. Dupuy H. J. The Psychological General Well-being (PGWB) index. In: Wenger, NK, Mattson, ME, Furberg, CD, Elinson, J, eds. Assessment of Quality of Life in Clinical Trials of Cardiovascular Therapies,New York: Le Jacq Publishing, 1984; 184-v

6. Bhogle, S. and Jai Prakash, I. Indicators of subjective well-being in a non-clinical sample. Psychological Studies, 1993; 38(3), 135-141

7. Dr L.I. Bhushan (Sannyasi Yogasindhu). An Instrument of Psychological Transformation Sivananda Math Yoga Magazine Bihar School of Yoga. 1998;9

8. Khumar, S. S., Kaur, P., Kaur, C. S. Effectiveness of Shavasana on depression among university students. Indian Journal of Clinical Psychology 1993, 9; 20(2), 82-87

9. Hafner-Holter, S., Kopp, M., Gunther,V. The effects of fitness training and yoga on well-being, stress, social competence, and body image. Neuropsychiatric 2009; 23(4): 244-8

10. Harvey, J. R. The effect of yogic breathing exercises on mood. Journal of American Society of Psychosomatic Dentistry and Medicine 1983; 30(2),39-48.

11. Khumar Kamakhya. Yog nidra and its impact on studens' well being; Yoga Mimansa, Kaivalyadhama, Lonawala ; 2004; Vol. 36 No.1

12. Khumar Kamakhya. A study of the improvement of Physical and Mental Health through Yog Nidra: Dev Sanskriti Journal, 2006; Vol. 4

13. Malathi, A. and Damodaran, A. Stress due to exams in medical students- Role of Yoga. Indian Journal of Physiology and Pharmacology 1999; 43(2):218-224.

14. Gupta N, Khera S, Vempati R. P., Sharma R., Bijlani R. L. Effect of yoga based life style intervention on state and trait anxiety. Indian Journal of Physiology Pharmacology 2006 JanMar; 50(1):41-7

15. Khumar Kamakhya. A study of the impact on the stress and anxiety through Yoga Nidra. Indian Journal of Traditional Knowledge 2008; Vols. 7 No.3

16. Michalsen , A., Grossman, P., et al 'Rapid stress reduction and anxiolysis among distressed woman as a consequence of a three-month intensive yoga program'. Med. Sci. Monit., 2005; $11,555-561$ 
17. Wood, C. Mood change and perceptions of vitality: a comparison of the effects of relaxation, visualization and yoga. Journal of the Royal Society of Medicine 1993; 86(5), 254-258. 5

18. Malathi, A. and Damodaran, A. Role of Yoga in relieving stress due to exams in medical students. Complementary Therapeutic Medicine 2006 June; 15(2): 77-83

19. Agte V.V., Chiplonkar, S. A. Sudarshan Kriya Yoga for Improving Antioxidant Status and Reducing Anxiety in Adults. Alternative Complementry Therapies 2008; 14 (2): 96-100

20. Oken B.S, Zajdel D, Kishiyama S, Flegal K, Dehen C, Haas M, Kraemer D.F, Lawrence J, Leyva J. Randomised controlled six-month trial of yoga in healthy seniors: effects on cognition and quality of life Alternative Therapeutic Health Medicine 2006 Jan-Feb; 12(1):40-7

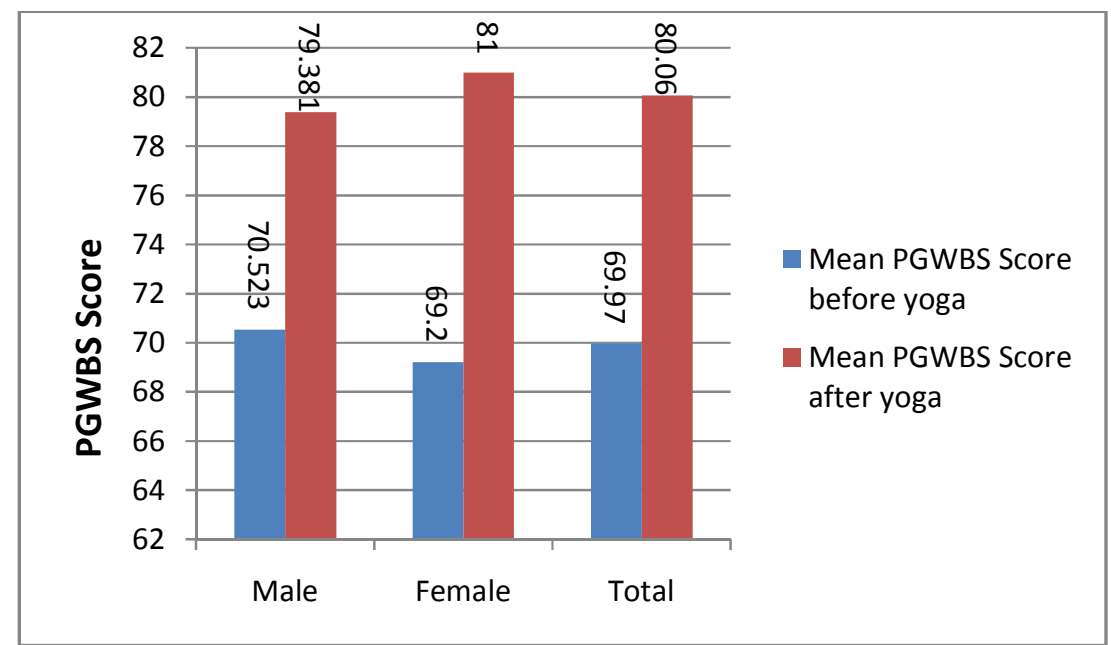

Fig. 1: Mean PGWBS Score in all subjects before and after yoga

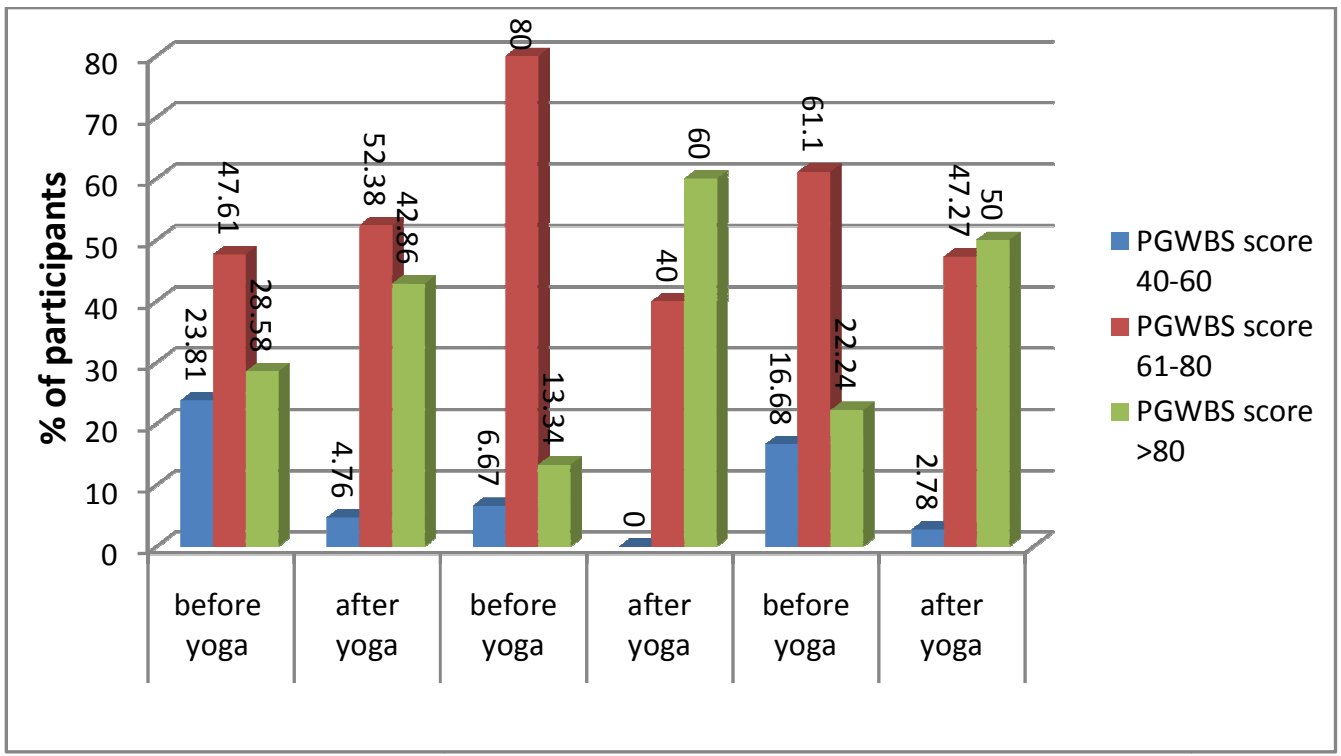

Fig 2: Percentage of subjects in various range of PGWBS before and after Yoga 